\title{
In Situ Probing Potassium-ion Intercalation-induced Amorphization in Crystalline Iron Phosphate Cathode Materials
}

\author{
Bertan Özdogru, Younghwan Cha, Vijay Murugesan, Min-Kyu Song and \\ Ö. Özgür Çapraz,
}

B. Özdogru, Prof. Ö. Ö. Çapraz

The School of Chemical Engineering

Oklahoma State University

Stillwater, OK 74078

Younghwan Cha, Prof. Min-Kyu Song,

School of Mechanical and Materials Engineering

Washington State University

Pullman, WA 99164

Vijay Murugesan

Pacific Northwestern National Laboratory,

902 Battelle Blvd, Richland, WA 99354 


\begin{abstract}
$\mathrm{Na}$-ion and $\mathrm{K}$-ion batteries are promising alternatives for large-scale energy storage applications due to their abundancy and lower cost. However, designing an electrode structure to reversibly accommodate these large alkali-ions is the remaining challenge before their commercialization. Intercalation of these large ions could cause irreversible structural deformations and amorphization in the crystalline electrodes. The designing of new amorphous electrodes is another route to develop electrodes to store these ions reversibly. Lack of understanding of dynamic changes in the amorphous nanostructures during battery operation is the bottleneck for further developments. Here, we report the utilization of in situ digital image correlation and in-operando X-ray diffraction (XRD) techniques to probe dynamic changes in the amorphous phase of iron phosphate during potassium intercalation. In-operando XRD demonstrates amorphization in the electrode's nanostructure during the first charge / discharge cycle. In situ strain analysis detects the reversible deformations associated with redox reactions in the amorphous phases. This method offers new insights to study mechanics of ion intercalation in the amorphous nanostructures.
\end{abstract}

Keywords: phase transformation, iron phosphate, amorphous, crystalline, potassium-ion batteries, electrochemical strains, $x$-ray diffraction 


\section{INTRODUCTION}

Rechargeable Li-ion batteries have been used to power consumer electronics and electric vehicles. The increasing demand on Li-ion batteries has created concern due to their limited and unevenly distributed resources. Rechargeable alkali metal-ion batteries with earth-abundant elements as charge carriers $(\mathrm{Na}$ and $\mathrm{K})$ are promising alternatives for large-scale energy devices and stationary storage $^{1}$. Na-ion (NIBs) and K-ion (KIBs) batteries are expected to share similar electrochemical properties with Li-ion batteries because they are monovalent ${ }^{2,3}$. However, many challenges remain to commercialize NIBs and KIBs including new electrode chemistries and mitigating chemo-mechanical degradations. Traditional electrode materials designed for Li-ion batteries may not be ideal to allow reversible charge storage of $\mathrm{Na}$ and $\mathrm{K}$ ions due to their different size, mass and reactivity. Intensive efforts have been focused to develop new electrode nanostructures for these battery systems ${ }^{4}$.

During insertion / removal of charge carriers, the electrode structures often undergo phase transformation, associated with the volume mismatch between the new phase and existing phase in the electrode particle. Depending on the phase transformation pathway and volume mismatch, insertion of alkali-ion into the host structure can cause plastic deformation, mechanical fracturing and even amorphization in the electrode. Insertion of Li-ions into silicon can cause up to $300 \%$ volumetric expansion and the extraordinary high transformation strain causes amorphization, which provides a desirable platform for hosting Li ions in the electrode ${ }^{5}$. The high transformation strains during $\mathrm{Na}$ intercalation into $\mathrm{FePO}_{4}(17 \%$ volume expansion) also cause the formation of amorphous phases between the primary phases, which is beneficial to alleviate the misfit strain energy ${ }^{6}$.

The traditional crystalline electrodes may not be able to accommodate the insertion of $\mathrm{Na}$ or $\mathrm{K}$ ions due to their size and reactivity with the host structure. For example, graphite structures allow reversible intercalation with Li ions, but are unable to host $\mathrm{Na}$ ions ${ }^{7-9}$. Layered metal oxides can only host a fraction of $\mathrm{K}$ ions, although they allow reversible cycling with $\mathrm{Li}$ and $\mathrm{Na}$ ions ${ }^{10-12}$. Unlike crystalline structures, the amorphous electrodes have short-range orders with long-range disordered structures. Due to the unique 
arrangement of atomic clusters in amorphous materials, they can store larger ions and provide flexibility to lattice distortions ${ }^{1}$. The amorphous materials can be identified easily by conventional X-ray diffraction (XRD) or electron microscopy techniques. The material chemistry of the amorphous materials also has been studied by utilizing Fourier-transform infrared spectroscopy, Raman spectroscopy and X-ray absorption spectroscopy. Although these techniques provide vital information about the chemistry of the amorphous materials, there is lack of understanding of the physical and dynamic behavior of amorphous materials during battery cycling. The chemo-mechanical analysis of dynamic changes in the amorphous materials as well as amorphization of crystalline structures during battery operation is very challenging due to the disordered nature of the amorphous phases.

Motivated by this, here, we propose a new experimental approach to monitor dynamic physical and structural changes in the amorphous phase of the electrodes by combining in situ strain measurements via digital image correlation (DIC) and in-operando XRD technique. Intercalation of $\mathrm{K}$ ions into crystalline iron phosphate, $\mathrm{FePO}_{4}$ host structure is chosen as a model system. Previous ex-situ XRD study demonstrated the amorphization of the crystalline $\mathrm{FePO}_{4}$ upon $\mathrm{K}$ intercalation ${ }^{13}$. XRD technique can detect crystallographic evolutions (e.g., interplanar spacing) and chemical composition of the crystalline structures. DIC technique has been used to characterize in situ electrochemical strain evolution in the composite electrodes associated with reversible (e.g., phase transformations) and irreversible (e.g., solid-electrolyte interface) deformations ${ }^{14-19}$. Previous DIC study investigated the relative strain evolutions upon $\mathrm{Na}$ and Li intercalation into $\mathrm{FePO}_{4}$ electrode and these relative strains were found to be much greater than relative expansions in electrode cell volume reported by the previous diffraction studies ${ }^{20}$. The discrepancy in volumetric changes in the electrode between XRD and DIC studies was associated with the formation of amorphous phase in the electrode upon Na-ion intercalation, which cannot be quantified by diffraction alone.

In this study, crystalline $\mathrm{FePO}_{4}$ electrode is first formed by utilizing electrochemical ion displacement method. Then, $\mathrm{K}$ ions were intercalated into the $\mathrm{FePO}_{4}$ electrode during in situ monitoring of electrochemical strain generation and structural changes by performing DIC and XRD techniques. The electrode lost its crystallinity during the first cycle and Bragg peaks did not show any significant changes in the subsequent 
cycles. On the other hand, the electrode showed reversible expansions and shrinkage in its volume upon discharge and charge cycles, respectively. The strain derivatives demonstrated a characteristic peak at specific potentials during $\mathrm{K}$ intercalation, which suggests reversible redox chemistry in the amorphous phase of the electrode.

The crystalline $\mathrm{FePO}_{4}$ host structure is generated by employing electrochemical displacement method ${ }^{21}$. Figures $1 \mathrm{~A}$ and $1 \mathrm{~B}$ show the voltage and strain evolution in the electrode during the removal of $\mathrm{Li}$ ions. The single potential plateau around $3.67 \mathrm{~V}$ vs $\mathrm{K} / \mathrm{K}^{+/ 0}$ indicates the formation of $\mathrm{Li}$-deficient $\mathrm{FePO}_{4}$ from $\mathrm{Li}$-rich $\mathrm{FePO}_{4}$, via a two phase reaction mechanism ${ }^{11,22}$. Delithiation capacity was calculated as $187 \mathrm{mAh} / \mathrm{g}$ and it is close to the theoretical capacity of lithium iron phosphate, $\mathrm{LiFePO}_{4}$, which is $170 \mathrm{mAh} / \mathrm{g}$. Removal of $\mathrm{Li}$ ions from $\mathrm{LiFePO}_{4}$ structure results in $0.18 \%$ contractions in the composite electrode (Figure 1B).
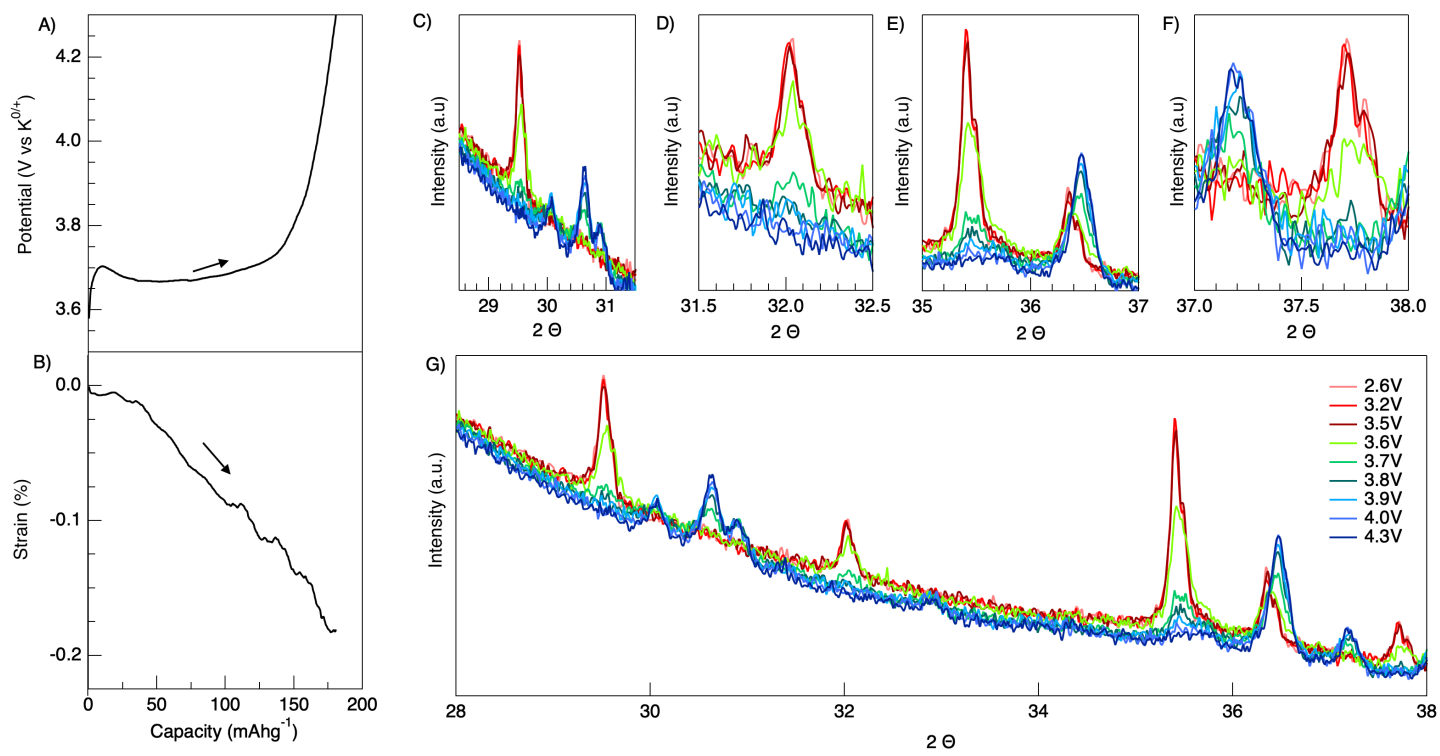

Figure 1: Formation of $\mathrm{FePO}_{4}$ electrode by electrochemical displacement of $\mathrm{Li}$ from $\mathrm{LiFePO}_{4}$ electrode. The pristine $\mathrm{LiFePO}_{4}$ electrode was delithiated at $\mathrm{C} / 10$ rate against $\mathrm{K}$ counter electrode until to $4.3 \mathrm{~V}$ vs $\mathrm{K} / \mathrm{K}^{+/ 0}$. (A) Voltage and (B) strain evolution during the extraction of $\mathrm{Li}$ ions from $\mathrm{LiFePO}_{4}$. The C-rate is calculated based on theoretical capacity of $\mathrm{LiFePO}_{4}$, which is $170 \mathrm{mAh} / \mathrm{g}$. (C-G) Evolution of $\mathrm{LiFePO}_{4}$ composite electrode's crystalline structure measured with in-operando XRD during electrochemical displacement process. Color change from red to blue indicates the increase in voltage as described in the figure. 
Figures 1C-1G show the evolution of crystalline structure of composite electrode during electrochemical displacement to remove $\mathrm{Li}$ from pristine $\mathrm{LiFePO}_{4}$ electrode. At the onset of the charge $(2.6 \mathrm{~V})$, the pristine electrode demonstrates well-defined XRD peaks around $29.5^{\circ}, 32^{\circ}, 35.5^{\circ}$ and $37.8^{\circ}$, which are associated with the crystalline structure of the $\mathrm{LiFePO}_{4}$ electrode ${ }^{11}$. During the process, the intensity of these peaks gradually decreases with the increase in voltage and eventually disappears at around $4.3 \mathrm{~V}$, which indicates the removal of $\mathrm{Li}$ ions from $\mathrm{LiFePO}_{4}$ structure. At the same time, new peaks started to appear around $30.5^{\circ}, 36.5^{\circ}$ and $37.2^{\circ}$, which are associated with $\mathrm{FePO}_{4}$ crystalline structure. Intensity of these peaks increases as more $\mathrm{Li}$ ions are removed from the crystalline structure, indicating the conversion of $\mathrm{LiFePO}_{4}$ to $\mathrm{FePO}_{4}$. Overall, the XRD patterns show the successful phase transition of the crystalline structure of the pristine $\mathrm{LiFePO}_{4}$ into $\mathrm{FePO}_{4}$ when the electrode was charged against $\mathrm{K}$ counter electrode.

After the formation of crystalline $\mathrm{FePO}_{4}$ structure with electrochemical displacement, the electrode is continuously discharged / charged with $\mathrm{K}$ ions at $\mathrm{C} / 25$ rate (Figure 2). During the first discharge, voltage sharply decreased to $2.3 \mathrm{~V}$ and showed a very small plateau around $2.3 \mathrm{~V}$. After the plateau region, voltage continued to decrease until the lower cutoff voltage of $1.5 \mathrm{~V}$. Discharge capacity was $43 \mathrm{mAh} / \mathrm{g}$. Intercalation of $\mathrm{K}$ into the $\mathrm{FePO}_{4}$ structure resulted in the electrode expanding about $0.66 \%$. The strains show non-linear increase with the discharge capacity (Supp. Fig. 1). Positions of the Bragg peaks in the $\mathrm{FePO}_{4}$ structure before the first discharge were recorded for (211), (020), (311) and (121). The initial structure of the electrode before the first discharge demonstrated typical $\mathrm{FePO}_{4}$ crystalline features ${ }^{23}$. Decrease of the intensity of the XRD peaks at $30.5^{\circ}$, $36.5^{\circ}$ and $37.2^{\circ}$ indicates the reduction in crystallinity of the electrode due to $\mathrm{K}$ ion insertion. These peaks are also shifted towards lower $2 \theta$, indicating the increase in interplanar spacing with the $\mathrm{K}$ ion intercalation. Supp. Table 1 shows the increase in the interplanar spacing along $<331>,<121>,<211>$ and $<020>$ by more than 0.5 pico meter at the end of the discharge cycle. No $\mathrm{LiFePO}_{4}$ peaks appeared during the first discharge.

During the first charge, voltage increased sharply until around $2.3 \mathrm{~V}$ voltage, and then it had shallower slope until the upper cutoff voltage of $4.3 \mathrm{~V}$. Charge capacity was about $40 \mathrm{mAh} / \mathrm{g}$. While the removal of the $\mathrm{K}$ after the first charge caused reduction of electrode volume, the electrode did not return to its original volume, resulting in an 
irreversible expansion of about $0.21 \%$ at the end of the first cycle. Increase in the intensity of the XRD peaks suggests the partial recovery of the electrode's crystallinity. Also, these peaks are shifted towards higher $2 \theta$, indicating the decrease in interplanar spacing due to removal of $\mathrm{K}$ ions.

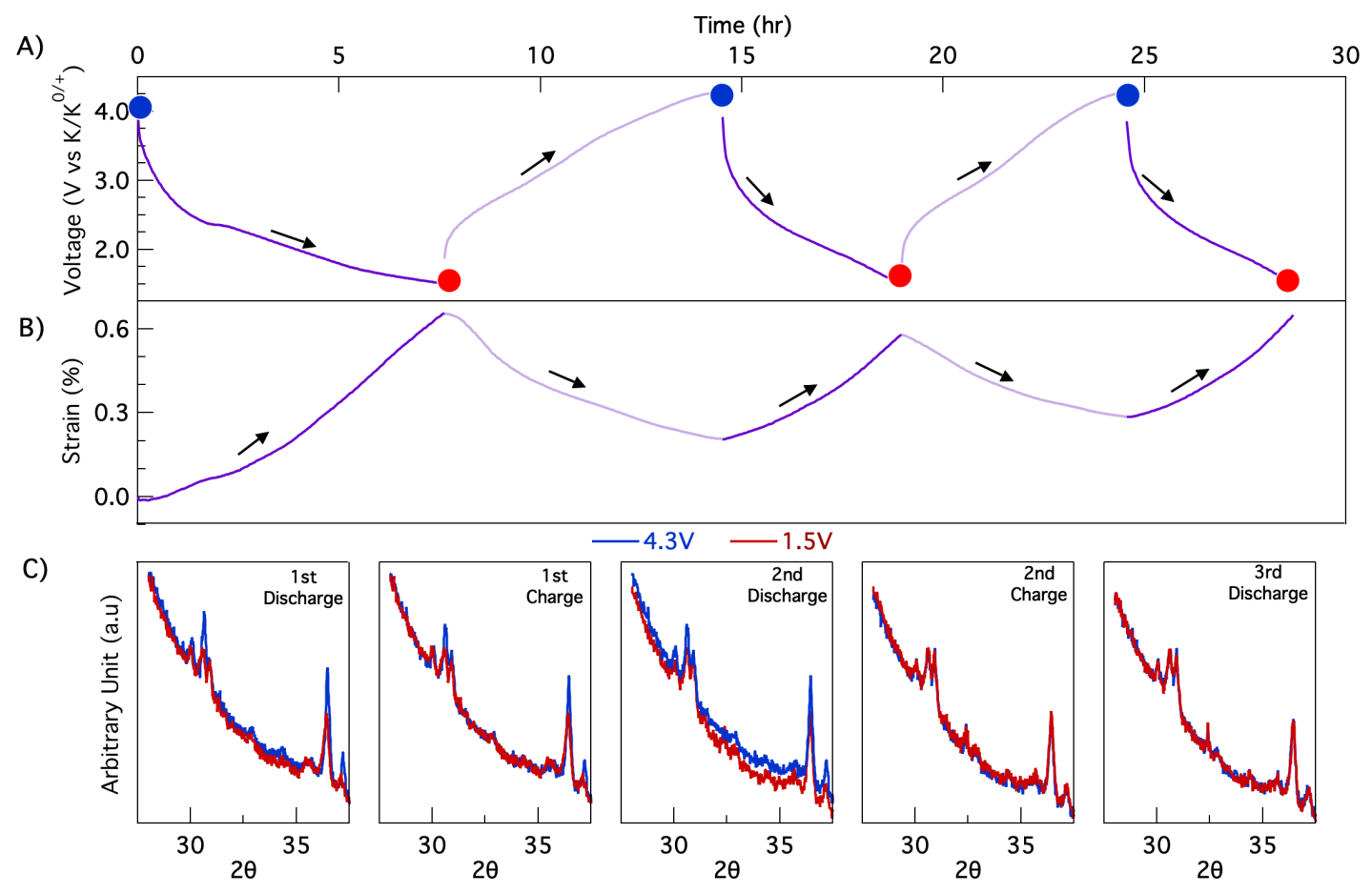

Figure 2: Discharge and Charge of $\mathrm{FePO}_{4}$ Composite electrode with $\mathrm{K}$ ions: A) Voltage and B) strain evolution in the composite electrode during $\mathrm{K}$ intercalation at $\mathrm{C} / 25$ rate. $\mathrm{C}$ ) Corresponding XRD patterns at the beginning and end of each charge and discharge cycles. Arrows indicates the direction of the cycles. The C-rate is calculated based on theoretical capacity of potassium iron phosphate, which is $141 \mathrm{mAh} / \mathrm{g}$.

In the subsequent discharge and charge cycles, intercalation of $\mathrm{K}$ into the cathode structure resulted in volumetric expansions and reductions, respectively. The difference in strain evolution between each charge and discharge cycle leads to increase in irreversible strains in the electrode, which becomes $0.41 \%$ by the end of the fourth cycle. Although both capacity and strain generation indicate the $\mathrm{K}$ ion intercalation into the electrode, intensity and location of the XRD peaks did not show any significant changes during the subsequent cycles. This indicates that crystallinity and interplanar spacing in the electrode does not change anymore in the crystalline part of the electrode and suggests that $\mathrm{K}$ ions are intercalated into the amorphized phase of the electrode. 
To better understand nanoscale structural changes in the electrode during charge and discharge cycles, capacity and strain derivatives with respect to voltage were calculated to investigate the charge behavior and physical response of the $\mathrm{FePO}_{4}$ electrode during $\mathrm{K}$ intercalation. Previous studies on graphite ${ }^{15,24}$, lithium manganese oxide (LMO) ${ }^{25-27}$, lithium iron phosphate (LFP) ${ }^{28}$ and sodium iron phosphate (NFP) ${ }^{21}$ electrodes showed that the evolution of the strain derivatives with potential closely matches with the phase transformations in the electrode structure. In the studies, the location of the strain derivative peaks was in good agreement with evolution of the electrochemical response of the materials associated with the nanoscale changes in their structure. Charging / discharging of graphite, LMO, LFP or NFP electrodes leads to changes in the crystalline structure associated with the phase transformations, which are well-reported by XRD studies. On the other hand, a previous ex-situ XRD study showed significant loss of crystallinity in the $\mathrm{FePO}_{4}$ structure after $\mathrm{K}$ intercalation, which is associated with the amorphization of the structure upon large $\mathrm{K}$ ion intercalation ${ }^{29}$.
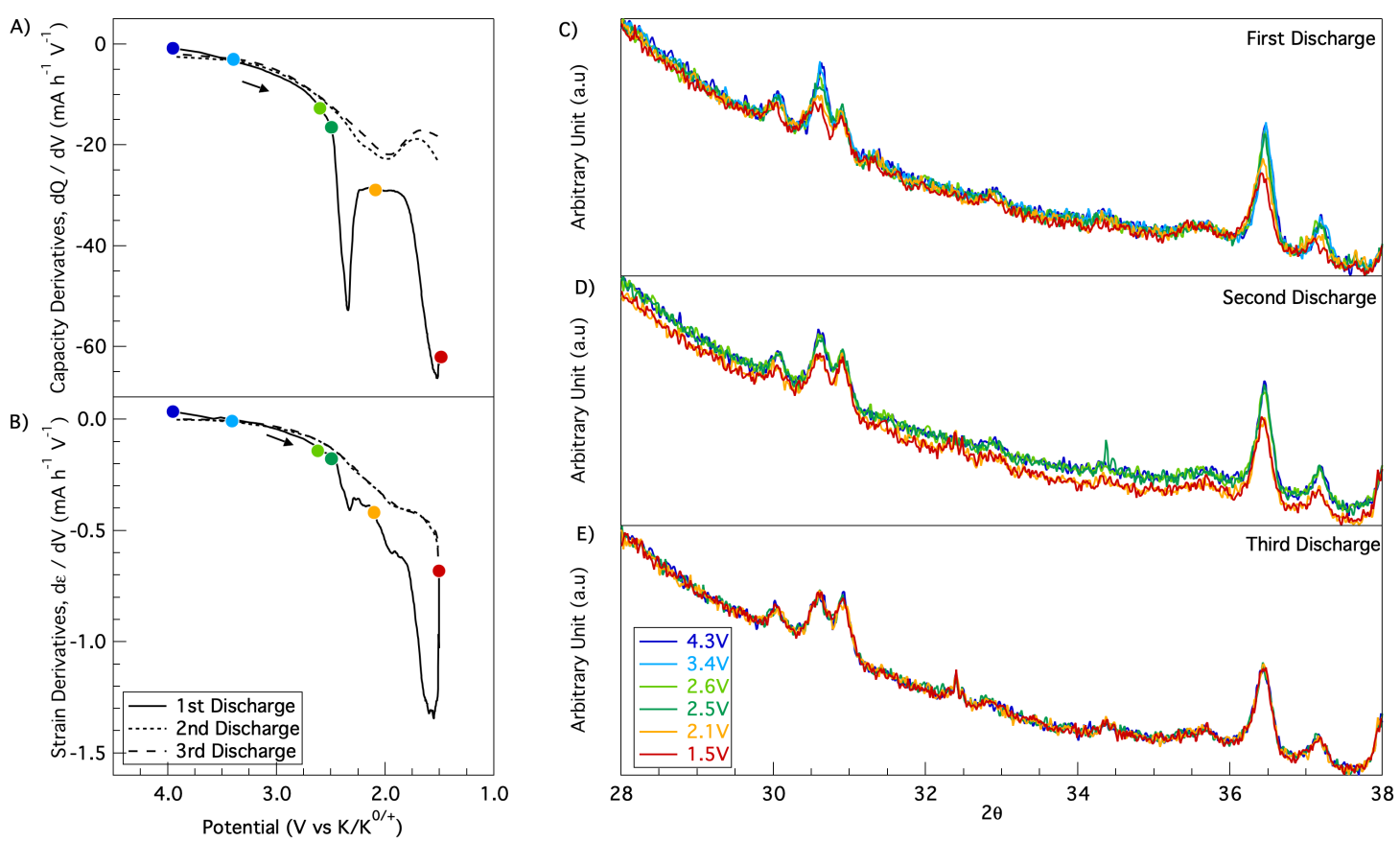

Figure 3: Structural, physical and electrochemical response of the iron phosphate during first three discharge cycles A) capacity and B) strain derivatives with respect to voltage. C-E) Corresponding XRD patterns at selected potentials colored as shown in the figure.

Strain and capacity derivatives are calculated by taking a derivative with respect to potential. Figure 3 shows the detailed picture of the progression in XRD peaks at selected 
voltages during discharge cycles, alongside the capacity and strain derivatives. During the first potassiation, two distinct strain derivative peaks were observed at around $2.3 \mathrm{~V}$ and $1.55 \mathrm{~V}$. The location of these peaks was closely aligned with the location of capacity derivatives within $3 \mathrm{mV}$. The absolute value of the strain and capacity derivatives at around $1.55 \mathrm{~V}$ were found to be greater than the ones at around $2.3 \mathrm{~V}$. Previous strain study demonstrated that the magnitude of the strain derivatives aligns well with the nanoscale changes in the electrode structure during $\mathrm{Li}$ intercalation into LMO cathodes. Therefore, the macroscale strain measurements are highly sensitive to nano-scale changes in the electrode structure ${ }^{27}$. On the other hand, intensity of the XRD peaks reduced slowly when the voltage was decreasing from about $3 \mathrm{~V}$ to $1.5 \mathrm{~V}$ during the first discharge cycle. Also, their location was slowly shifted toward higher $2 \theta$ while inserting more $\mathrm{K}$ ions into the electrode structure. Previous study based on amorphous $\mathrm{FePO}_{4}$ showed the formation of $\mathrm{KFe}_{2}\left(\mathrm{PO}_{4}\right)_{2}$ crystalline structure during the first $\mathrm{K}$ intercalation in the electrode structure ${ }^{30}$.

Strain and capacity derivative peaks around $2.3 \mathrm{~V}$ and $1.55 \mathrm{~V}$ disappeared in the consecutive potassiation cycles. A single characteristic peak in capacity derivative emerged at around $1.9 \mathrm{~V}$. The rate of strain derivatives also changed at around $1.9 \mathrm{~V}$ in the subsequent discharge cycle, demonstrated as a shoulder in Figure 3B. On the other hand, both location and intensity of the Braggs peaks did not change during the $2^{\text {nd }}$ and $3^{\text {rd }}$ discharge cycles. The combination of XRD and strain derivative analysis suggests the reversible electrochemical reaction and associated structural changes in the amorphous phase of the $\mathrm{FePO}_{4}$ at around $1.9 \mathrm{~V}$.

Figure 4 shows the detailed picture of the progression in XRD peaks at selected voltages during charge cycles, alongside the capacity and strain derivatives. During the first depotassiation, there are three minima peaks in capacity derivatives at around 2.8, 3.2 and $3.8 \mathrm{~V}$. The associated peaks in the strain derivatives are clearly observed at 2.8 and $3.8 \mathrm{~V}$. The strain derivative had a shoulder at around $3.2 \mathrm{~V}$, which aligns with the location of the capacity derivative peak in $3.2 \mathrm{~V}$. The magnitude of the strain derivative peak at $2.8 \mathrm{~V}$ was greater than the other detected strain derivative peaks during the charge cycle. On the other hand, both location and intensity of the Braggs peaks were almost the same until the higher voltages towards the end of the first charge cycle. The increases in the peak intensities were detected above around $4.0 \mathrm{~V}$ and the peaks were shifted to lower $2 \theta$. In the 
subsequent charge cycles, derivative peaks in 3.2 and $3.8 \mathrm{~V}$ disappeared and there was only one characteristic peak observed in both strain and capacity derivatives at around $2.8 \mathrm{~V}$. On the other hand, both location and intensity of the Braggs peaks did not change during the $2^{\text {nd }}$ charge cycle. The combination of strain analysis with in situ XRD data suggests the phase transformation in the amorphous phase of the electrode at around $2.8 \mathrm{~V}$ during charge cycles.
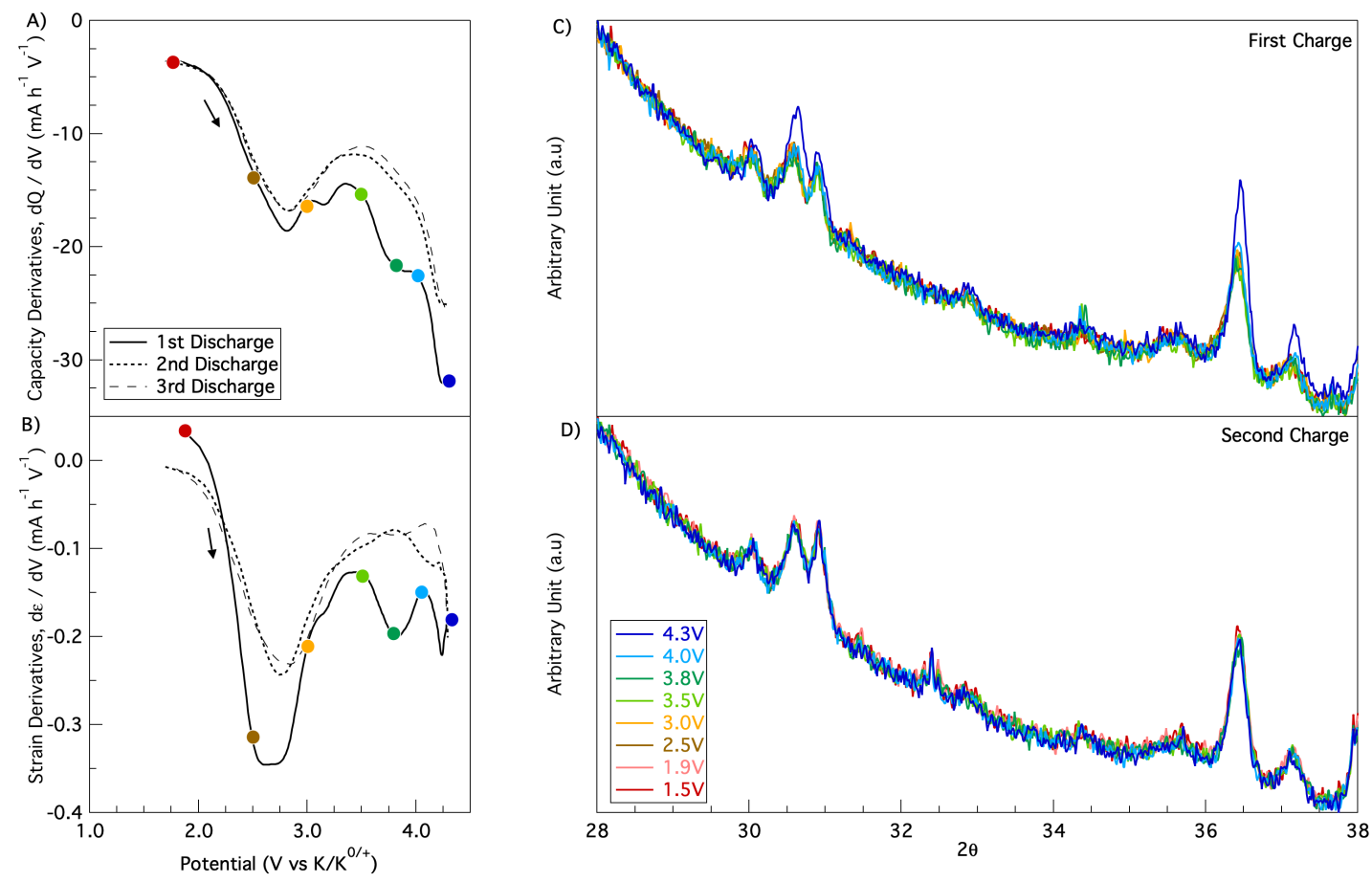

Figure 4: Structural, physical and electrochemical response of the $\mathrm{FePO}_{4}$ during charge cycles A) capacity and B) strain derivatives with respect to voltage. C-D) Corresponding XRD patterns at selected potentials colored as shown in the figure.

To examine the impact of the electrolyte decomposition on the capacity and strain derivatives during $\mathrm{K}$ intercalation into $\mathrm{FePO}_{4}$ cathodes, the electrode was also cycled in $0.5 \mathrm{M} \mathrm{KPF}_{6}$ in PC electrolyte (Supp. Figure 4-6). The evolution of the strain derivative peak during the first discharge cycle was significantly different than the subsequent discharge cycles. The electrode demonstrated two distinct strain and capacity derivative peaks at around 2.8 and $3.8 \mathrm{~V}$ during the first charge cycle. Like the strain behavior of the electrode when cycled in EC: DMC solvent, the peak at around 3.8V disappeared in the subsequent charge cycles. Beyond the first cycle, the electrode experiences reversible strain and capacity derivatives around the similar potentials when the electrode cycled in either 
EC: DMC or PC solvent, pointing out that the behavior of charge and physical response in the electrode is associated with the changes in the electrode structure. Also, in both cases, the magnitude of the strain derivatives at the end of the first discharge cycle is significantly larger than the ones at the subsequent discharge cycles, regardless of the electrolyte. Overall, strain derivative analysis suggests a significant structural deformation during the first cycle and electrodes demonstrate reversible mechanical and electrochemical responses in the subsequent cycles.

Interestingly, the distinct differences between the first cycle and the subsequent cycles during $\mathrm{K}$ intercalation into $\mathrm{FePO}_{4}$ are observed in both strain measurements and XRD analysis. In-operando XRD analysis demonstrated the changes in the electrode structure during the first cycle and in-situ strain analysis showed irreversible strain and capacity derivatives only observed during the first cycle. Beyond the first cycle, the electrode no longer undergoes any detectable changes in its crystallinity in the XRD analysis. Both evolution profile of the strain and capacity derivatives become highly reversible beyond the first cycle. Surprisingly, although in-operando XRD analysis was not able to capture any changes in the crystalline structure of the electrode during the subsequent cycles, strain derivatives analysis indicates a reversible physical change in the electrode as a result of redox chemistry in the electrode upon reversible $\mathrm{K}$ ion intercalation. The reversible strain and capacity derivatives suggest the phase transformations in the electrode structure at redox potentials of $1.9 \mathrm{~V}$ during discharge and $2.8 \mathrm{~V}$ during charge cycles, respectively.

Identifying the redox reactions in the amorphous phase and its associated volumetric changes upon $\mathrm{K}$ intercalation into amorphous phase is an important step to understand the dynamic and kinetic changes in the amorphous electrodes. We foresee that a similar approach can be utilized to study chemo-mechancs of amorphous electrodes for many different battery chemistries including Na-ion, $\mathrm{K}$-ion and $\mathrm{Zn}$-ion batteries. In situ probing of dynamic changes in the amorphous materials during battery cycling can provide fundemantal knowledge to establish a structure - mechanics- performance relationship for amorphous materials. 


\section{Supporting Information}

The Supporting Information is available free of charge on the ACS Publications website, including additional details of experimental methods, a table showing the change in interplanar spacing during electrochemical displacement of ions, figures showing strain vs capacity relationships, and figures showing voltage and strain profiles in different electrolytes.

\section{AUTHOR INFORMATION}

\section{Corresponding Author}

* Ömer Özgür Çapraz, ocapraz@,okstate.edu

The School of Chemical Engineering, Oklahoma State University, Stillwater, OK 74078

\section{Author Contributions}

The manuscript was written through contributions of all authors. All authors have given approval to the final version of the manuscript. $\$$ and B. O. and Y. C. contributed equally. Ö. Ö. Ç conceived the idea and supervised the work. B. O. prepared cathode slurries and performed in situ strain measurements. Y. C. and M. S. performed in-operando XRD measurements and analysis. All authors discussed the results. The authors declare that they have no competing interests. All data needed to evaluate the conclusions in the paper are present in the paper and/or the Supporting information. Additional data related to this paper may be requested from the authors.

\section{Funding Sources}

This work was supported by the U.S. Department of Energy, Office of Science, Basic Energy Sciences (Award number DE-SC0021251). VM acknowledges funding as part of the Joint Center for Energy Storage Research, an Energy Innovation hub funded by the U.S. Department of Energy, Office of Science, Basic Energy Science. 


\section{REFERENCES}

(1) Wei, Z.; Wang, D.; Yang, X.; Wang, C.; Chen, G.; Du, F. From Crystalline to Amorphous: An Effective Avenue to Engineer High-Performance Electrode

Materials for Sodium-Ion Batteries. Adv. Mater. Interfaces 2018, 5 (19). https://doi.org/10.1002/admi.201800639.

(2) Hwang, J.-Y.; Myung, S.-T.; Sun, Y.-K. Sodium-Ion Batteries: Present and Future. Chem. Soc. Rev. 2017, 46 (12), 3529-3614. https://doi.org/10.1039/C6CS00776G.

(3) Pasta, M.; Wessells, C. D.; Liu, N.; Nelson, J.; Mcdowell, M. T.; Huggins, R. A.; Toney, M. F.; Cui, Y. ARTICLE Full Open-Framework Batteries for Stationary Energy Storage. Nat. Commun. 2014, 5. https://doi.org/10.1038/ncomms4007.

(4) Xiong, F.; Tao, H.; Yue, Y. Role of Amorphous Phases in Enhancing Performances of Electrode Materials for Alkali Ion Batteries. Frontiers in Materials. Frontiers Media S.A. January 8, 2020. https://doi.org/10.3389/fmats.2019.00328.

(5) McDowell, M. T.; Lee, S. W.; Nix, W. D.; Cui, Y. 25th Anniversary Article: Understanding the Lithiation of Silicon and Other Alloying Anodes for Lithium-Ion Batteries. Advanced Materials. September 2013, pp 4966-4985. https://doi.org/10.1002/adma.201301795.

(6) Xiang, K.; Xing, W.; Ravnsbæk, D. B.; Hong, L.; Tang, M.; Li, Z.; Wiaderek, K. M.; Borkiewicz, O. J.; Chapman, K. W.; Chupas, P. J.; et al. Accommodating High Transformation Strains in Battery Electrodes via the Formation of Nanoscale Intermediate Phases: Operando Investigation of Olivine NaFePO4. Nano Lett. 2017, 17 (3), 1696-1702. https://doi.org/10.1021/acs.nanolett.6b04971.

(7) Komaba, S.; Murata, W.; Ishikawa, T.; Yabuuchi, N.; Ozeki, T.; Nakayama, T.; Ogata, A.; Gotoh, K.; Fujiwara, K. Electrochemical Na Insertion and Solid Electrolyte Interphase for Hard-Carbon Electrodes and Application to Na-Ion Batteries. Adv. Funct. Mater. 2011, 21 (20), 3859-3867. https://doi.org/10.1002/adfm.201100854.

(8) Irisarri, E.; Ponrouch, A.; Palacin, M. R. Review-Hard Carbon Negative Electrode Materials for Sodium-Ion Batteries. J. Electrochem. Soc. 2015, 162 (14), A2476A2482. https://doi.org/10.1149/2.0091514jes.

(9) Li, Y.; Lu, Y.; Adelhelm, P.; Titirici, M. M.; Hu, Y. S. Intercalation Chemistry of 
Graphite: Alkali Metal Ions and Beyond. Chemical Society Reviews. Royal Society of Chemistry September 7, 2019, pp 4655-4687. https://doi.org/10.1039/c9cs00162j.

(10) Van Der Ven, A.; Deng, Z.; Banerjee, S.; Ong, S. P. Rechargeable Alkali-Ion Battery Materials: Theory and Computation. Chemical Reviews. American Chemical Society 2020. https://doi.org/10.1021/acs.chemrev.9b00601.

(11) Kubota, K.; Dahbi, M.; Hosaka, T.; Kumakura, S.; Komaba, S. Towards K-Ion and Na-Ion Batteries as "Beyond Li-Ion." Chem. Rec. 2018, 18 (4), 459-479. https://doi.org/10.1002/tcr.201700057.

(12) Hosaka, T.; Kubota, K.; Hameed, A. S.; Komaba, S. Research Development on KIon Batteries. Chemical Reviews. American Chemical Society 2020. https://doi.org/10.1021/acs.chemrev.9b00463.

(13) Recham, N.; Rousse, G.; Sougrati, M. T.; Chotard, J. N.; Frayret, C.; Mariyappan, S.; Melot, B. C.; Jumas, J. C.; Tarascon, J. M. Preparation and Characterization of a Stable FeSO4F-Based Framework for Alkali Ion Insertion Electrodes. Chem. Mater. 2012, 24 (22), 4363-4370. https://doi.org/10.1021/cm302428w.

(14) Jones, E. M. C.; Silberstein, M. N.; White, S. R.; Sottos, N. R. In Situ Measurements of Strains in Composite Battery Electrodes during Electrochemical Cycling. Exp. Mech. 2014, 54 (6), 971-985. https://doi.org/10.1007/s11340-014-9873-3.

(15) Tavassol, H.; Jones, E. M. C.; Sottos, N. R.; Gewirth, A. A. Electrochemical Stiffness in Lithium-Ion Batteries. Nat. Mater. 2016, 15 (11), 1182-1188. https://doi.org/10.1038/nmat4708.

(16) Çapraz, Ö. Ö.; Bassett, K. L.; Gewirth, A. A.; Sottos, N. R. Electrochemical Stiffness Changes in Lithium Manganese Oxide Electrodes. Adv. Energy Mater. 2017. https://doi.org/10.1002/aenm.201601778.

(17) Jones, E. M. C.; Çapraz, Ö. Ö.; White, S. R.; Sottos, N. R. Reversible and Irreversible Deformation Mechanisms of Composite Graphite Electrodes in Lithium-Ion Batteries. J. Electrochem. Soc. 2016, 163 (9), A1965-A1974. https://doi.org/10.1149/2.0751609jes.

(18) Eastwood, D. S.; Yufit, V.; Gelb, J.; Gu, A.; Bradley, R. S.; Harris, S. J.; Brett, D. J. L.; Brandon, N. P.; Lee, P. D.; Withers, P. J.; et al. Lithiation-Induced Dilation 
Mapping in a Lithium-Ion Battery Electrode by 3D X-Ray Microscopy and Digital Volume Correlation. Adv. Energy Mater. 2014, 4 (4), 1300506. https://doi.org/10.1002/aenm.201300506.

Qi, Y.; Harris, S. J. In Situ Observation of Strains during Lithiation of a Graphite Electrode. J. Electrochem. Soc. 2010, 157 (6), A741. https://doi.org/10.1149/1.3377130.

(20) Özdogru, B.; Dykes, H.; Padwal, S.; Harimkar, S.; Çapraz, Ö. Ö.; Özdogru, B.; Dykes, H.; Çapraz, Ö. Ö. Electrochemical Strain Evolution in Iron Phosphate Composite Cathodes During Lithium and Sodium Ion Intercalation. Electrochim. Acta 2020, 136594. https://doi.org/10.1016/j.electacta.2020.136594.

(21) Özdogru, B.; Dykes, H.; Padwal, S.; Harimkar, S.; Çapraz, Ö. Electrochemical Strain Evolution in Iron Phosphate Composite Cathodes during Lithium and Sodium Ion Intercalation. Electrochim. Acta $2020, \quad 353$. https://doi.org/10.1016/j.electacta.2020.136594.

(22) Zhu, Y.; Xu, Y.; Liu, Y.; Luo, C.; Wang, C. Comparison of Electrochemical Performances of Olivine NaFePO4 in Sodium-Ion Batteries and Olivine LiFePO4 in Lithium-Ion Batteries. Nanoscale 2013, $5 \quad$ (2), 780-787. https://doi.org/10.1039/c2nr32758a.

(23) Heubner, C.; Heiden, S.; Schneider, M.; Michaelis, A. In-Situ Preparation and Electrochemical Characterization of Submicron Sized NaFePO4 Cathode Material for Sodium-Ion Batteries. Electrochim. Acta 2017, 233, 78-84. https://doi.org/10.1016/j.electacta.2017.02.107.

(24) Jones, E. M. C.; Çapraz, Ö. Ö.; White, S. R.; Sottos, N. R. Reversible and Irreversible Deformation Mechanisms of Composite Graphite Electrodes in Lithium-Ion Batteries. J. Electrochem. Soc. 2016, 163 (9), A1965-A1974. https://doi.org/10.1149/2.0751609jes.

(25) Çapraz; Rajput, S.; Bassett, K. L.; Gewirth, A. A.; White, S. R.; Sottos, N. R. Controlling Expansion in Lithium Manganese Oxide Composite Electrodes via Surface Modification. J. Electrochem. Soc. 2019, 166 (12), A2357-A2362. https://doi.org/10.1149/2.0021912jes.

(26) Çapraz; Rajput, S.; White, S.; Sottos, N. R. Strain Evolution in Lithium Manganese 
Oxide Electrodes. Exp. Mech. 2018, 58 (4), 561-571. https://doi.org/10.1007/s11340-018-0381-8.

(27) Çapraz, Ö. Ö.; Bassett, K. L.; Gewirth, A. A.; Sottos, N. R. Electrochemical Stiffness Changes in Lithium Manganese Oxide Electrodes. Adv. Energy Mater. 2017, 7 (7), 1601778. https://doi.org/10.1002/aenm.201601778.

(28) Bassett, K. L.; Özgür Çapraz, Ö.; Özdogru, B.; Gewirth, A. A.; Sottos, N. R. Cathode/Electrolyte Interface-Dependent Changes in Stress and Strain in Lithium Iron Phosphate Composite Cathodes. J. Electrochem. Soc. 2019, 166 (12), A2707A2714. https://doi.org/10.1149/2.1391912jes.

(29) Hosaka, T.; Shimamura, T.; Kubota, K.; Komaba, S. Polyanionic Compounds for Potassium-Ion Batteries. Chem. Rec. 2019, 19 (4), 735-745. https://doi.org/10.1002/tcr.201800143.

(30) Mathew, V.; Kim, S.; Kang, J.; Gim, J.; Song, J.; Baboo, J. P.; Park, W.; Ahn, D.; Han, J.; Gu, L.; et al. Amorphous Iron Phosphate: Potential Host for Various Charge Carrier Ions. NPG Asia Mater. 2014, 6 (10). https://doi.org/10.1038/am.2014.98. 